\title{
Differential effects of nutrient-limited primary production on primary, secondary or tertiary consumers
}

\author{
Arne M. Malzahn • Florian Hantzsche • \\ Katherina L. Schoo • Maarten Boersma • \\ Nicole Aberle
}

Received: 12 December 2008/Accepted: 28 August 2009/Published online: 26 September 2009

(C) Springer-Verlag 2009

\begin{abstract}
Nutritional imbalances between predator and prey are the rule rather than the exception at the lower end of food webs. We investigated the role of different grazers in the propagation of nutritionally imbalanced primary production by using the same primary producers in a threetrophic-level food chain and a four-trophic-level food chain experimental setup. The three-trophic-level food chain consisted of a classic single-cell primary producer (Rhodomonas salina), a metazoan grazer (the copepod Acartia tonsa) and a top predator (the jellyfish Gonionemus vertens), while we added a protozoan grazer (Oxyrrhis marina) as primary consumer to the food chain to establish the four-trophic-level food chain. This setup allowed us to investigate how nutrient-limitation effects change from one trophic level to another, and to investigate the performance of two components of our experimental food chains in different trophic positions. Stoichiometry and fatty acid
\end{abstract}

Communicated by Sebastian Diehl.

Electronic supplementary material The online version of this article (doi:10.1007/s00442-009-1458-y) contains supplementary material, which is available to authorized users.

A. M. Malzahn $(\bowtie) \cdot$ F. Hantzsche · K. L. Schoo .

M. Boersma $\cdot$ N. Aberle

Alfred-Wegener-Institut für Polar- und Meeresforschung,

Biologische Anstalt Helgoland, Postbox 180,

27483 Helgoland, Germany

e-mail: Arne.Malzahn@awi.de

A. M. Malzahn · F. Hantzsche - M. Boersma GKSS-Research Centre, Institute for Coastal Research, Max-Planck-Straße 1, 21502 Geesthacht, Germany

K. L. Schoo

IFM-GEOMAR, Leibniz Institute for Marine Sciences,

Düsternbrooker Weg 20, 24105 Kiel, Germany profiles of the algae showed significant differences between the nutrient-depleted [no $\mathrm{N}$ and no $\mathrm{P}$ addition $(-\mathrm{P})$, respectively] and the nutrient-replete (f/2) treatments. The differences in stoichiometry could be traced when O. marina was the first consumer. Copepods feeding on these flagellates were not affected by the nutritional imbalance of their prey in their stoichiometry, their respiration rates nor in their developmental rates. In contrast, when copepods were the primary consumer, those reared on the $-\mathrm{P}$ algae showed significantly higher respiration rates along with significantly lower developmental rates. In neither of our two experimental food chains did the signals from the base of the food chains travel up to jelly fish, our top predator.

Keywords Stoichiometry - Copepods - Jellyfish . Food chain length · Trophic transfer

\section{Introduction}

In ecological research the issue of nutritional quality and its effect on consumers have been the focus of attention for many years (Sterner and Elser 2002). Most of the studies on transfer efficiencies between trophic levels have, however, concentrated solely on the link between primary producers and herbivores, focusing mainly on algae and microcrustaceans in aquatic systems (Gulati and DeMott 1997) and leaves and leaf-eating insects in terrestrial systems (Elser et al. 2000). There are good reasons for this, since primary producers usually reflect the nutrient ratios of their surrounding environment, while their consumers are constrained with respect to their body $\mathrm{C}: \mathrm{N}: \mathrm{P}$ ratios, which remain much more constant. This phenomenon is referred to as homeostasis (Elser et al. 2000), leading to frequent imbalances between food supply and the demands 
of the consumers. Consequently, all consumers have developed mechanisms to cope with these fluctuations in food quality (Hessen and Anderson 2008). Usually C supply exceeds the demand, while $\mathrm{N}$ and $\mathrm{P}$ are often the limiting elements. To meet the consumers' nutrient demand in the light of excess $\mathrm{C}$, a good proportion of the ingested $\mathrm{C}$ has to be excreted or stored, and both mechanisms involve costs. This can be achieved by the consumers by extra muscular activity, e.g. an increase in appendage beat rate in cladocerans (Plath and Boersma 2001), thermogenesis as described for locusts (Zanotto et al. 1997), or enhanced respiration by using low-efficiency metabolic pathways such as futile cycles (Newsholme et al. 1972) and oxidative phosphorylation uncoupling (Jindra and Sehnal 1990). Furthermore, consumers can simply excrete excess C.

Another widespread argument for the focus of research on the interface between primary production and herbivores is that even if homeostasis of primary consumers failed to dampen nutrient imbalances between prey and consumer, the remaining imbalances between these primary consumers and their predators are small compared to those regularly observed between primary producers and herbivores and are therefore of minor ecological relevance (Sterner and Elser 2002). Based upon these two arguments, hardly any work exists investigating nutrient transfer in a stoichiometric context to higher trophic levels. Only recently, it has been shown that secondary consumers suffer from nutrient imbalances when these are not completely dampened by primary consumers in aquatic systems. This has been proven in controlled laboratory studies (Boersma et al., in press; Malzahn et al. 2007; Schoo et al. 2009) and in less-controlled more natural mesocosm studies (Dickman et al. 2008). At the same time, this has also been shown for terrestrial systems, e.g. for carnivorous beetles by Kagata and Ohgushi (2007) in an experimental three-trophic-level food chain setup, and in a broader sense by Denno and Fagan (2003) who showed that even minor differences, usually found between predator and prey $\mathrm{N}$ stoichiometry, shape omnivory, but information on this specific field of research is still very limited.

Interestingly for aquatic environments, quite a number of studies on the role of heterotrophic flagellates as trophic upgraders are available, which show that heterotrophic protists are a better food source for zooplankters than algae. Most of these studies focused on essential macromolecules such as fatty acids (e.g. Bec et al. 2006; Chu et al. 2008), that were either enriched or synthesized in the flagellates. Potentially, this increase in food quality can also be a result of a more balanced or more buffered stoichiometry of macronutrients such as $\mathrm{N}$ or P. Unfortunately, virtually nothing is known about nutrient homeostasis in protozoan grazers, with the exception of the work by Goldman et al. (1987), who studied grazer-induced nutrient cycling and showed that protist grazers retain scarce elements, but their retention efficiency was low compared to those of metazoans (Andersen et al. 1986). Similar findings are reported from a modelling study by Grover and Chrzanowski (2006). Their results suggest that the homeostatic ability of protozoans is low compared to metazoan grazers, and that they dampen nutritional imbalances of their prey only to a certain degree. As a result, they might represent food of a better quality compared to primary producers; however, they can by no means be considered as food of quasi-constant quality for higher trophic levels.

It is clear that $\mathrm{C}: \mathrm{N}: \mathrm{P}$ ratios are bulk measures, and there is an ongoing debate on whether stoichiometry alone is capable of describing feeding-related processes (growth, reproduction, recycling) on various levels of organisation or whether individual measures of biochemical compounds such as fatty acids, lipid classes or amino acids should be used to better understand these processes (Anderson et al. 2004). Fatty acids, for instance, play a major role in this discussion (Müller-Navarra 1995) and their important role in consumers' nutrition is unquestioned. Especially the essential fatty acids (i.e. the ones that cannot be synthesised de novo by most consumers) are of interest, as their concentration in primary consumers might be a useful predictor for consumers' growth and the concentrations are dependent on algal species as well as on the growing conditions of algae (Malzahn et al. 2007; Reitan et al. 1997). To get a more comprehensive picture of the nature of, e.g. consumer growth limitation, especially in experiments using single algal species as the base of food chains, the combination of fatty acid and nutrient stoichiometry analyses is useful (Anderson and Pond 2000).

Here we hypothesize that more complex food webs, e.g. those having an herbivorous microzooplankton component, are a sink of excess $\mathrm{C}$ while macronutrients are retained, and that the incorporation of an intermediary microzooplankton component to the prey of omnivorous animals enhances the condition of higher order consumers. To test this hypothesis, we conducted two experiments using highly controlled food chains consisting of three and four trophic levels where we confronted the respective two and three consumer levels with nutrient-limited and nutrientreplete primary production at the base of the food chain. Due to the ecological relevance of gelatinous predatory zooplankton as voracious predators (Lynam et al. 2005; Purcell and Arai 2001) and their predicted increase in relevance and biomass in the light of global change scenarios (Attrill et al. 2007; Mills 2001) we chose Gonionemus vertens, a limnomedusae which only recently invaded the shallow North Sea (Bakker 1980), as top predator in our experiments. Rhodomonas salina served as 
primary producer and the flagellate Oxyrrhis marina and the copepod Acartia tonsa as first and second consumer, respectively.

\section{Materials and methods}

In order to investigate upward travelling nutrient ( $\mathrm{N}$ and $\mathrm{P}$ ) effects through several trophic levels, we established two experimental food chains. The first consisted of three trophic levels, namely algae, copepods, and jellyfish. We added another consumer, a heterotrophic nanoflagellate, to the second food chain resulting in four trophic levels. It served as the primary consumer in the four-trophic-level experimental food chain and hence shifted copepods and jellyfish one trophic level up compared to the three-trophiclevel food chain. These food chains were reared under three nutrient regimes, and each compartment of our 'trophic assembly lines' was reared in individual containers, to ensure that e.g. the copepods of the four-trophic-level food chain fed on heterotrophs and not on the heterotrophs' algal prey. This setting allowed us to investigate effects of food chain length as well as species-specific responses of consumers to the trophic level they were feeding upon. To investigate the effect of food quality rather than food quantity, we adjusted the amount of food fed to the consumer levels to equal amounts for the three nutrient treatments. The whole experiment was conducted in a single effort to minimize variability in food quality.

\section{Phytoplankton}

A stock culture of the cryptophyte Rhodomonas salina was cultivated in enriched seawater $\left(\mathrm{f} / 2 ; 8.83 \times 10^{-4}\right.$ mol $\mathrm{NaNO}_{3} 1^{-1}$ and $3.63 \times 10^{-5} \mathrm{~mol} \mathrm{NaH}_{2} \mathrm{PO}_{4} 1^{-1}$ ), following Guillard and Ryther (1962). For our experiments, we cultivated algae at $18^{\circ} \mathrm{C}$ under a 16:8-h (light:dark) light regime in nutrient-enriched natural seawater (salinity $\sim 32$ ), as well as under nutrient limitation (here: $\mathrm{P}$ and $\mathrm{N}$ ). Prior to the experiment, the whole water used for culturing algae during the experiments was $0.2-\mu \mathrm{m}$ sterile filtered in one effort and stored cool and dark until use. The first nutrient treatment consisted of $\mathrm{f} / 2$-enriched seawater, as described by Guillard and Ryther (1962). The algae of the two limitation treatments were also enriched after Guillard and Ryther (1962), but without the addition of the limiting nutrient [minus $\mathrm{P}(-\mathrm{P})$ or minus-N $(-\mathrm{N})$ ] and could therefore only utilize the natural $\mathrm{P}$ or $\mathrm{N}$ sources present in the seawater at the moment of filtration. This kind of treatment ensured a limitation of the desired nutrient by enriching the media with the other nutrients (i.e. $\mathrm{N}$ or $\mathrm{P}$, vitamins, and metals) in excess. Several tests on algal growth rates were conducted prior to the experiments to detect the "carrying capacity" of the three different media and to define the duration required until the algae were properly limited by the element of choice in the different nutrient treatments. Concentrations of algae were determined using a particle counter (Schärfe System, CASY cell counter and analyser system).

To ensure constant food quality, new cultures of each of the nutrient treatments were inoculated every day with roughly $0.2 \times 10^{6}$ cells $\mathrm{ml}^{-1}$ for the $\mathrm{f} / 2$ treatment and $-\mathrm{N}$ treatment and $0.3 \times 10^{6}$ cells $\mathrm{ml}^{-1}$ for the $-\mathrm{P}$ treatment. Algae were harvested at densities of approximately 0.6 , 1.0 , and $1.3 \times 10^{6}$ cells $\mathrm{ml}^{-1}(-\mathrm{N},-\mathrm{P}$, and $\mathrm{f} / 2$, respectively) after a predefined growth phase of 4 days.

\section{Heterotrophic nanoflagellates}

A stock culture of the heterotrophic nanoflagellate Oxyrrhis marina was cultivated on the stock cultures of $R$. salina described above. The experimental manipulation of the heterotrophic flagellates was realized by incubating them at

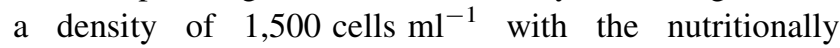
manipulated $R$. salina described above $(\mathrm{f} / 2,-\mathrm{N}$, and $-\mathrm{P}$ ) for 4 days at densities of $5 \mathrm{mg} \mathrm{C}^{-1}$ (approximately $83 \times 10^{9}$ cells $1^{-1}$ ) in plastic bags in dimmed light. The algae were supplied in a single feeding event. This was necessary to ensure that all algae were ingested by $O$. marina after 4 days to guarantee that: (1) no algae were fed to the copepods along with the O. marina, and (2) no algae were sampled along with the $O$. marina and entered the biochemical analysis. This was tested using the particle counter (Schärfe System, CASY cell counter and analyser system). Again, to ensure constant food quality, new cultures of each of the treatments were inoculated every day.

\section{Copepods}

Eggs of the calanoid copepod Acartia tonsa had been produced in 200-1 cylindrical tanks, where the animals were cultivated at $18^{\circ} \mathrm{C}$ at a $12: 12$-h light cycle. In these tanks copepods were fed a mixture of the algae $R$. salina and the flagellate $O$. marina. Eggs were siphoned from the bottom of the tanks daily and stored in seawater at $4^{\circ} \mathrm{C}$ for later use. No eggs older than 3 months were used during the experiments.

The stored eggs were incubated in artificial seawater. The hatching rate of the eggs was around $20 \%$. The copepods used for the experiments were reared from the egg to copepodite stages in $5-1$ plastic bags at $18^{\circ} \mathrm{C}$ at densities of 1,300 individuals (ind.) $1^{-1}$. The cultured algae were fed to the copepods of the three-trophic-level food chain at approximately $1.0 \mathrm{mg} \mathrm{C}^{-1}$ day $^{-1}$ on 8 consecutive days; the copepods of the four-trophic-level food chain were fed on $O$. marina for 8 consecutive days at 
approximately $1.0 \mathrm{mg} \mathrm{C}^{-1} \mathrm{day}^{-1}$. During the experiment we estimated the amount of cells needed to feed the desired amount of $R$. salina and $O$. marina; later analysis revealed that our estimations were reasonable. In order to guarantee that the algal deficiencies were not changed by uptake of nutrients during the incubations with the heterotrophic organisms, the primary consumers (A. tonsa as well as $O$. marina) were reared in artificial, $\mathrm{N}$ - and $\mathrm{P}$-free seawater which was adjusted to a salinity of 30 [salt (hw-Marinemix, www.hw-wiegandt.de), in deionised water]. Copepods were first fed $48 \mathrm{~h}$ after the addition of the eggs to the rearing bags, assuming a 2-day developmental period from the egg to the first feeding second naupliar stage. On each day of the feeding experiment, three new copepod bags (one for each nutrient treatment) were started to ensure a constant food quality for the top consumer, the jellyfish Gonionemus vertens. Copepods were harvested after 10 days of cultivation and developmental stages were determined. No discrimination between naupliar stages was conducted, while copepodites were determined for their developmental stage. Developmental rates (stages day ${ }^{-1}$ ) were calculated in a conservative way, by assigning all naupliar larvae to stage 6. Approximately $70 \%$ of all individuals reached copepodite stages and the other $30 \%$ were still naupliar when they were fed to the jellyfish. As we kept all culture parameters constant during the trial, final copepod density (ind. $\mathrm{ml}^{-1}$ ) was used as a proxy for survival.

\section{Jellyfish}

The limnomedusae G. vertens were taken from stock cultures and transferred individually to 1-1 bottles equipped with a glass tube for the limnomedusae to adhere to. The natural habitat of this jellyfish species is seagrass meadows, where they attach to seagrass leaves and let themselves fall down to the sea bottom in regular intervals. While falling to the sea bottom they spread their tentacles in order to hunt zooplankton (Bakker 1980). Prior to the experiments the jellyfishes' performance under our artificial culture conditions were tested. The jellyfish attached to the glass tubes, i.e. they used them as substitute for seagrass leaves. The jellyfish were fed the experimentally manipulated copepods on 8 consecutive days at densities of 0.60.8 ind. $\mathrm{ml}^{-1}$ for all nutrient treatments. Water was exchanged daily to ensure a high water quality and that leftover copepods were removed and only fresh prey was available for the jellyfish.

Analytical procedures

Samples of algae, heterotrophic flagellates and copepods were taken every day when they were fed to the next consumer; jellyfish were sampled at the end of the experiment. For the analysis of $\mathrm{C}$ and $\mathrm{N}$ contents of algae and the heterotrophic flagellates, an estimated $300 \mu \mathrm{g} \mathrm{C}$ was filtered on pre-combusted Whatman GF/F filter. For the analysis of copepod C, 50 individuals were collected into tin capsules. Jellyfish were pulverized by adding glass beads (mixture of 1.0-mm and 0.17- to 0.34-mm-diameter beads) to the freeze-dried samples and shaking them for $5 \mathrm{~min}$ in a cell mill. An approximately $500-\mu \mathrm{g}$ sample was weighed into tin capsules. The freeze-dried samples were analysed at the University of California Davis Stable Isotope Facility (Department of Plant Sciences, University of California Davis, Calif.) using a PDZ Europa ANCA-GSL element analyser. Samples for the analysis of $\mathrm{P}$ content were duplicates of those used for the $\mathrm{C}$ and $\mathrm{N}$ analysis with the difference that the jellyfish powder was weighed into glass tubes instead of tin capsules. The freeze-dried samples were analysed for their $\mathrm{P}$ content as orthophosphate after acidic oxidative hydrolysis with $5 \% \mathrm{H}_{2} \mathrm{SO}_{4}$ (Grasshoff et al. 1999). C:N, C:P and $\mathrm{N}: \mathrm{P}$ ratios are given as molar ratios.

The fatty acids of algae, heterotrophic flagellates, copepods and jellyfish were measured as fatty acid methyl esters (FAMEs). Lipids were extracted from the samples by a modification of the methods described by Folch et al. (1957) and Bligh and Dyer (1959). Samples for fatty acid analyses were extracted in dichloromethane:methanol (2:1 vol:vol) in an ultrasound bath for $30 \mathrm{~min}$. Water-soluble fractions were removed after centrifugation by washing with $0.88 \% \mathrm{KCl}$ buffer. The aqueous phase was removed and the organic remainder was evaporated using $\mathrm{N}$ gas. The esterification was achieved using methanolic-sulphuric acid at $70^{\circ} \mathrm{C}$ for $75 \mathrm{~min}$. The FAMEs were washed from the methanolic sulphuric acid using n-hexane. Excess n-hexane was evaporated using $\mathrm{N}$ gas. All chemicals used were Suprasolv or GC grade. FAMEs were analysed by gas chromatography using a Varian CP 8400 gas chromatograph equipped with a DB-225 column $(30 \mathrm{~m}$ length, $0.25 \mathrm{~mm}$ internal diameter, $0.25-\mu \mathrm{m}$ film; J\&W Scientific). The injector temperature was set to $250^{\circ} \mathrm{C}$. The column oven was set to $60^{\circ} \mathrm{C}$, which was held for $1 \mathrm{~min}$ after injection. The oven was heated to $150^{\circ} \mathrm{C}$ at $15^{\circ} \mathrm{C} \min ^{-1}$, then to $170^{\circ} \mathrm{C}$ at $3{ }^{\circ} \mathrm{C} \mathrm{min}^{-1}$, and finally to $220^{\circ} \mathrm{C}$ at $1^{\circ} \mathrm{C}$ $\mathrm{min}^{-1}$, which was held for $21 \mathrm{~min}$. The carrier gas was $\mathrm{He}$ at a constant pressure of $82.737 \mathrm{~Pa}$. The flame ionisation detector was set to $300^{\circ} \mathrm{C}$. The injection of the $1-\mu \mathrm{l}$ aliquots of the samples was done in a splitless mode. FAMEs were quantified using calibrations set up for each fatty acid separately and a known amount of C 23:0 was added at the first step of the preparation as an internal standard.

Copepod respiration rates $\left(\mu \mathrm{g} \mathrm{O}_{2} \mathrm{~min}^{-1}\right)$ were determined by means of a four-channel microsensor oxygen meter (PreSens-Precision Sensing, Germany) equipped 
with oxygen microoptodes. Copepods were sieved (100- $\mu \mathrm{m}$ mesh size) in order to avoid primary producers entering the incubation vessel and three copepods were transferred to each incubation chamber (2-ml volume, filled with artificial seawater). Copepods were allowed to adapt to the new environment for $5 \mathrm{~min}$ before the measurement started. Copepod respiration was measured for $6 \mathrm{~min}$. Respiration rates were calculated by linearly regressing oxygen concentrations versus time.

The nutritional condition of the jellyfish was assessed by means of the analysis of the ratio between RNA and DNA content in the organisms, a method commonly used in larval fish ecology and fisheries research. The analysis of RNA and DNA concentrations of jellyfish tissue was performed using a modification of the method by Clemmesen (1993). Pulverized sample $(200 \mu \mathrm{g})$ was weighed (Sartorius microbalance $\mathrm{SC} 2$ ) for the nucleic acid analysis. The tissue powder was rehydrated in TRIS-sodium dodecyl sulphate (SDS)-buffer (0.05 mol TRIS $1^{-1}, 0.01 \mathrm{~mol} \mathrm{NaCl}$ $1^{-1}, 0.01 \mathrm{~mol}$ ethylenediaminetetraacetic acid $1^{-1}, 0.01 \%$ SDS) for $15 \mathrm{~min}$. Cells were disrupted by shaking in a cellmill with different-sized glass beads (mixture of $1.0 \mathrm{~mm}$ and $0.17-0.34 \mathrm{~mm}$ in diameter) for $15 \mathrm{~min}$. The homogenate was then centrifuged at 6,000 r.p.m. at $0^{\circ} \mathrm{C}$ for $8 \mathrm{~min}$, and the supernatant used for the analysis. The amount of nucleic acids was measured fluorometrically in a microtiter fluorescence reader (Fluorescan Ascent; Labsystems) using the fluorophor ethidiumbromide. Total nucleic acids were measured first and RNAse was then applied to the sample in order to digest the RNA. After the enzyme treatment (30 min at $37^{\circ} \mathrm{C}$ ) the remaining DNA was measured. The RNA fluorescence was calculated by subtracting the DNA fluorescence from the total nucleic acid fluorescence. RNA calibrations were set up every measurement day. The DNA concentrations were calculated using the relationship between RNA and DNA fluorescence described by Le Pecq and Paoletti (1966).

\section{Statistical analysis}

$\mathrm{C}: \mathrm{P}, \mathrm{C}: \mathrm{N}$, and $\mathrm{N}: \mathrm{P}$ as well as fatty acids of phytoplankton and heterotrophic flagellates were analysed as dependent variables with a one-factorial ANOVA using nutrient treatment as the factor. Stoichiometric measures, fatty acids, respiration rates, copepod survival and developmental rates of the copepods were analysed in a twofactorial ANOVA using nutrient treatment and trophic level as independent factors and the stoichiometric measures as dependent variables. Jellyfish fatty acid measures and the RNA:DNA response to the different nutrient treatments were analysed in a two-factorial design with nutrient treatment and trophic level as independent factors and the RNA:DNA or the fatty acid measures as the dependent variable. Tukey's honest significant difference test was used as the post hoc test in all cases.

\section{Results}

R. salina

The primary producers grown under $\mathrm{N}$ - or P-depleted and nutrient-replete conditions showed significant differences in their nutrient stoichiometry (Table 1) as well as in their fatty acid profiles (Table 2; Table 1 online supplement). The $\mathrm{C}: \mathrm{N}$ ratio of the algae grown under $\mathrm{N}$-depleted conditions was significantly increased when compared to $\mathrm{P}$ - and nutrient-replete growth conditions (Fig. 1a). The $\mathrm{C}: \mathrm{P}$ ratio of the $-\mathrm{P}$ algae differed significantly from the other two nutrient treatments (Fig. 1b). The same pattern was found in the N:P ratio (Fig. 1c).

The fatty acid profiles of the algae showed significant differences between the nutrient treatments, with generally higher fatty acid concentrations in the two nutrient-deficient treatments (Fig. 2a; Table 1; Table 1 online supplement). This was not only true for the total fatty acid concentrations, but also for the concentration of unsaturated fatty acids as well as the $n 3$ and n6 fatty acids, making the nutrient-deficient algae a favourable food in terms of their fatty acid profiles.

\section{O. marina}

The stoichiometry of $O$. marina was significantly affected by the stoichiometry of their food. O. marina reared on $\mathrm{N}$-stressed algae showed a significantly higher $\mathrm{C}: \mathrm{N}$ ratio than those reared on the other two N-replete treatments (7.0, 8.5, and 7.3 for $\mathrm{f} / 2,-\mathrm{N}$, and $-\mathrm{P}$ respectively; Fig. 1a; Table 1). Similarly, the C:P ratio for $O$. marina reared on $\mathrm{P}$-stressed algae was elevated compared to the other treatments (180, 217, and 385 for $\mathrm{f} / 2,-\mathrm{N}$, and $-\mathrm{P}$, respectively; Fig. 1b; Table 1). Finally, O. marina feeding on the P-stressed food chain showed significantly enhanced $\mathrm{N}: \mathrm{P}$ values $(25,25$ and 52 for $-\mathrm{N}, \mathrm{f} / 2$ and $-\mathrm{P}$, respectively; Fig. 1c; Table 1). Summarizing these results, $O$. marina did not completely dampen the nutritional imbalances of its prey.

The fatty acid profiles of $O$. marina showed an interesting pattern, as they were significantly enriched in some fatty acids compared to their algal prey (Fig. 2a, b; Table 2 online supplement). 16:0, docosapentaenoic acid (22:5n3), as well as docosahexaenoic acid (22:6n3) and consequently the corresponding bulk measures (total fatty acids, total saturated fatty acids, total unsaturated fatty acids, and n3 fatty acids) were significantly enriched in relation to their prey. The exception was $R$. salina grown under N-limited conditions, which showed some exceptionally high values 
Table 1 Summary of the ANOVA

${ }^{a} R$. salina and $O$. marina $\mathrm{C}: \mathrm{N}$, $\mathrm{C}: \mathrm{P}$ and $\mathrm{N}: \mathrm{P}$ were analysed by a one-factorial ANOVA using nutrient treatment as the independent factor and $\mathrm{C}: \mathrm{N}, \mathrm{C}: \mathrm{P}$ or $\mathrm{N}: \mathrm{P}$ as the dependent variables

b Stochiometric measures of $A$. tonsa were analysed in a twofactorial ANOVA using trophic level and nutrient treatment as independent factors and the stoichiometric measures, respiration rate and developmental rates as dependent variables

c G. vertens data were analysed in a two-factorial design with trophic level and nutrient treatment as independent factors and the jelly fish RNA:DNA ratio as the dependent variable

\begin{tabular}{|c|c|c|c|c|}
\hline Organism & Factor & & $d f(d f$ error $)$ & $P$ \\
\hline \multirow[t]{3}{*}{ R. salina ${ }^{\mathrm{a}}$} & $\mathrm{C}: \mathrm{N}$ & Treatment (Treat). & $2(27)$ & $<0.05$ \\
\hline & $C: P$ & Treatment & $2(27)$ & $<0.05$ \\
\hline & $\mathrm{N}: \mathrm{P}$ & Treatment & $2(27)$ & $<0.05$ \\
\hline \multirow[t]{3}{*}{ O. marina ${ }^{\mathrm{a}}$} & $\mathrm{C}: \mathrm{N}$ & Treatment & $2(27)$ & $<0.05$ \\
\hline & $C: P$ & Treatment & $2(27)$ & $<0.05$ \\
\hline & $\mathrm{N}: \mathrm{P}$ & Treatment & $2(27)$ & $<0.05$ \\
\hline \multirow[t]{18}{*}{ A. tonsa ${ }^{\mathrm{b}}$} & $\mathrm{C}: \mathrm{N}$ & Treatment & 2 & 0.19 \\
\hline & & Trophic level (Tr. lev.) & 1 & $<0.05$ \\
\hline & & Treat. $\times$ Tr. lev. & $2(41)$ & $<0.05$ \\
\hline & $\mathrm{C}: \mathrm{P}$ & Treatment & 2 & 0.66 \\
\hline & & Trophic level & 1 & 0.92 \\
\hline & & Treat. $\times$ Tr. lev. & $2(39)$ & 0.45 \\
\hline & $\mathrm{N}: \mathrm{P}$ & Treatment & 2 & 0.46 \\
\hline & & Trophic level & 1 & 0.45 \\
\hline & & Treat. $\times$ Tr. lev. & $2(39)$ & 0.18 \\
\hline & log Survival & Treatment & 2 & 0.11 \\
\hline & & Trophic level & 1 & $<0.05$ \\
\hline & & Treat. $\times$ Tr. lev. & $2(39)$ & 0.53 \\
\hline & Respiration & Treatment & 2 & $<0.05$ \\
\hline & & Trophic level & 1 & $<0.05$ \\
\hline & & Treat. $\times$ Tr. lev. & $2(39)$ & $<0.05$ \\
\hline & Development & Treatment & 2 & $<0.05$ \\
\hline & & Trophic level & 1 & $<0.05$ \\
\hline & & Treat. $\times$ Tr. lev. & $2(39)$ & 0.51 \\
\hline \multirow[t]{12}{*}{ G. vertens ${ }^{\mathrm{c}}$} & $\mathrm{C}: \mathrm{N}$ & Treatment & 2 & 0.82 \\
\hline & & Trophic level & 1 & 0.69 \\
\hline & & Treat. $\times$ Tr. lev. & $2(50)$ & 0.24 \\
\hline & $\log \mathrm{C}: \mathrm{P}$ & Treatment & 2 & $<0.05$ \\
\hline & & Trophic level & 1 & 0.87 \\
\hline & & Treat. $\times$ Tr. lev. & $2(50)$ & $<0.05$ \\
\hline & $\mathrm{N}: \mathrm{P}$ & Treatment & 2 & $<0.05$ \\
\hline & & Trophic level & 1 & 0.91 \\
\hline & & Treat. $\times$ Tr. lev. & $2(50)$ & $<0.05$ \\
\hline & RNA:DNA & Treatment & 2 & 0.17 \\
\hline & & Trophic level & 1 & $<0.05$ \\
\hline & & Treat. $\times$ Tr. lev. & $2(51)$ & $<0.05$ \\
\hline
\end{tabular}

in the $18 \mathrm{C}$ unsaturated fatty acids as well as high eicosapentaenoic acid levels (Fig. 2a). Another interesting result was that there were only few differences in the fatty acid measures of $O$. marina among treatments, although the fatty acid composition of the algae differed strongly among the nutrient treatments (Fig. 2b). Nevertheless, there was a reaction to the ingested food, as the concentration of saturated fatty acids was significantly enhanced in $O$. marina fed on N-depleted algae, which themselves showed significantly increased saturated fatty acid concentrations in comparison to the other algal nutrient treatments.

\section{A. tonsa}

We first describe the effects of the nutrient treatments separately for the cases when Acartia was on the second and on the third trophic level. We then describe effects of the trophic-level treatments.

\section{A. tonsa as first consumer}

The C:N ratio of $A$. tonsa fed on $\mathrm{f} / 2$ algae was significantly lower than that of the other two nutrient treatments (Fig. 1d; 
Table 2 Summary of the ANOVA on various fatty acid sum parameters

\begin{tabular}{|c|c|c|c|c|}
\hline Organism & Factor & & $d f(d f$ error $)$ & $P$ \\
\hline \multirow[t]{7}{*}{ R. salina ${ }^{\mathrm{a}}$} & Total fatty acids & Treatment (Treat.) & $2(27)$ & $<0.05$ \\
\hline & Saturated fatty acids (Sat.) & Treatment & $2(27)$ & $<0.05$ \\
\hline & Unsaturated fatty acids (Unsat.) & Treatment & $2(27)$ & $<0.05$ \\
\hline & Sat.:Unsat. & Treatment & $2(27)$ & 0.12 \\
\hline & n3 fatty acids & Treatment & $2(27)$ & $<0.05$ \\
\hline & n6 fatty acids & Treatment & $2(27)$ & $<0.05$ \\
\hline & n3:n6 fatty acids & Treatment & $2(27)$ & $<0.05$ \\
\hline \multirow[t]{7}{*}{ O. marina $^{\mathrm{a}}$} & Total fatty acids & Treatment & $2(27)$ & 0.65 \\
\hline & Saturated fatty acids & Treatment & $2(27)$ & $<0.05$ \\
\hline & Unsaturated fatty acids & Treatment & $2(27)$ & 0.81 \\
\hline & Sat.:Unsat. & Treatment & $2(27)$ & 0.10 \\
\hline & n3 fatty acids & Treatment & $2(27)$ & 0.15 \\
\hline & n6 fatty acids & Treatment & $2(27)$ & 0.19 \\
\hline & n3:n6 fatty acids & Treatment & $2(27)$ & $<0.05$ \\
\hline \multirow[t]{21}{*}{ A. tonsa $^{\mathrm{b}}$} & Total fatty acids & Treatment & 2 & $<0.05$ \\
\hline & & Trophic level (Tr. lev.) & 1 & 0.24 \\
\hline & & Treat. $\times$ Tr. lev & $2(37)$ & 0.20 \\
\hline & Saturated fatty acids & Treatment & 2 & $<0.05$ \\
\hline & & Trophic level & 1 & 0.51 \\
\hline & & Treat. $\times$ Tr. lev. & $2(37)$ & 0.99 \\
\hline & Unsaturated fatty acids & Treatment & 2 & 0.51 \\
\hline & & Trophic level & 1 & 0.29 \\
\hline & & Treat. $\times$ Tr. lev. & $2(37)$ & 0.07 \\
\hline & Sat:unsat fatty acids & Treatment & 2 & 0.33 \\
\hline & & Trophic level & 1 & 0.28 \\
\hline & & Treat. $\times$ Tr. lev & $2(37)$ & $<0.05$ \\
\hline & n3 fatty acids & Treatment & 2 & 0.53 \\
\hline & & Trophic level & 1 & 0.30 \\
\hline & & Treat. $\times$ Tr. lev & $2(37)$ & 0.13 \\
\hline & n6 fatty acids & Treatment & 2 & 0.09 \\
\hline & & Trophic level & 1 & 0.67 \\
\hline & & Treat. $\times$ Tr. lev. & $2(37)$ & $<0.05$ \\
\hline & n3:n6 fatty acids & Treatment & 2 & $<0.05$ \\
\hline & & Trophic level & 1 & 0.17 \\
\hline & & Treat. $\times$ Tr. lev. & $2(37)$ & 0.69 \\
\hline \multirow[t]{21}{*}{ G. vertens ${ }^{\mathrm{b}}$} & Total fatty acids & Treatment & 3 & 0.33 \\
\hline & & Trophic level & 1 & 0.30 \\
\hline & & Treat. $\times$ Tr. lev & $3(68)$ & 0.64 \\
\hline & Saturated fatty acids & Treatment & 3 & 0.29 \\
\hline & & Trophic level & 1 & 0.70 \\
\hline & & Treat. $\times$ Tr. lev & $3(68)$ & $<0.05$ \\
\hline & Unsaturated fatty acids & Treatment & 3 & 0.24 \\
\hline & & Trophic level & 1 & 0.26 \\
\hline & & Treat. $\times$ Tr. lev. & $3(68)$ & 0.70 \\
\hline & Sat:Unsat fatty acids & Treatment & 3 & 0.47 \\
\hline & & Trophic level & 1 & 0.22 \\
\hline & & Treat. $\times$ Tr. lev. & $3(68)$ & 0.66 \\
\hline & n3 fatty acids & Treatment & 3 & 0.11 \\
\hline & & Trophic level & 1 & 0.32 \\
\hline & & Treat. $\times$ Tr. lev & $3(68)$ & 0.58 \\
\hline & n6 fatty acids & Treatment & 3 & 0.11 \\
\hline & & Trophic level & 1 & 0.20 \\
\hline & & Treat. $\times$ Tr. lev & $3(68)$ & 0.50 \\
\hline & n3:n6 fatty acids & Treatment & 3 & 0.21 \\
\hline & & Trophic level & 1 & 0.35 \\
\hline & & Treat. $\times$ Tr. lev. & $3(68)$ & 0.58 \\
\hline
\end{tabular}

${ }^{\text {a }} R$. salina and $O$. marina data were analysed by a one-factorial ANOVA using nutrient treatment as the independent factor and fatty acid measures as the dependent variables

${ }^{\mathrm{b}}$ Fatty acid measures of $A$. tonsa and $G$. vertens were analysed in a two-factorial ANOVA using trophic level and nutrient treatment as independent factors and the fatty acid measures as dependent variables 

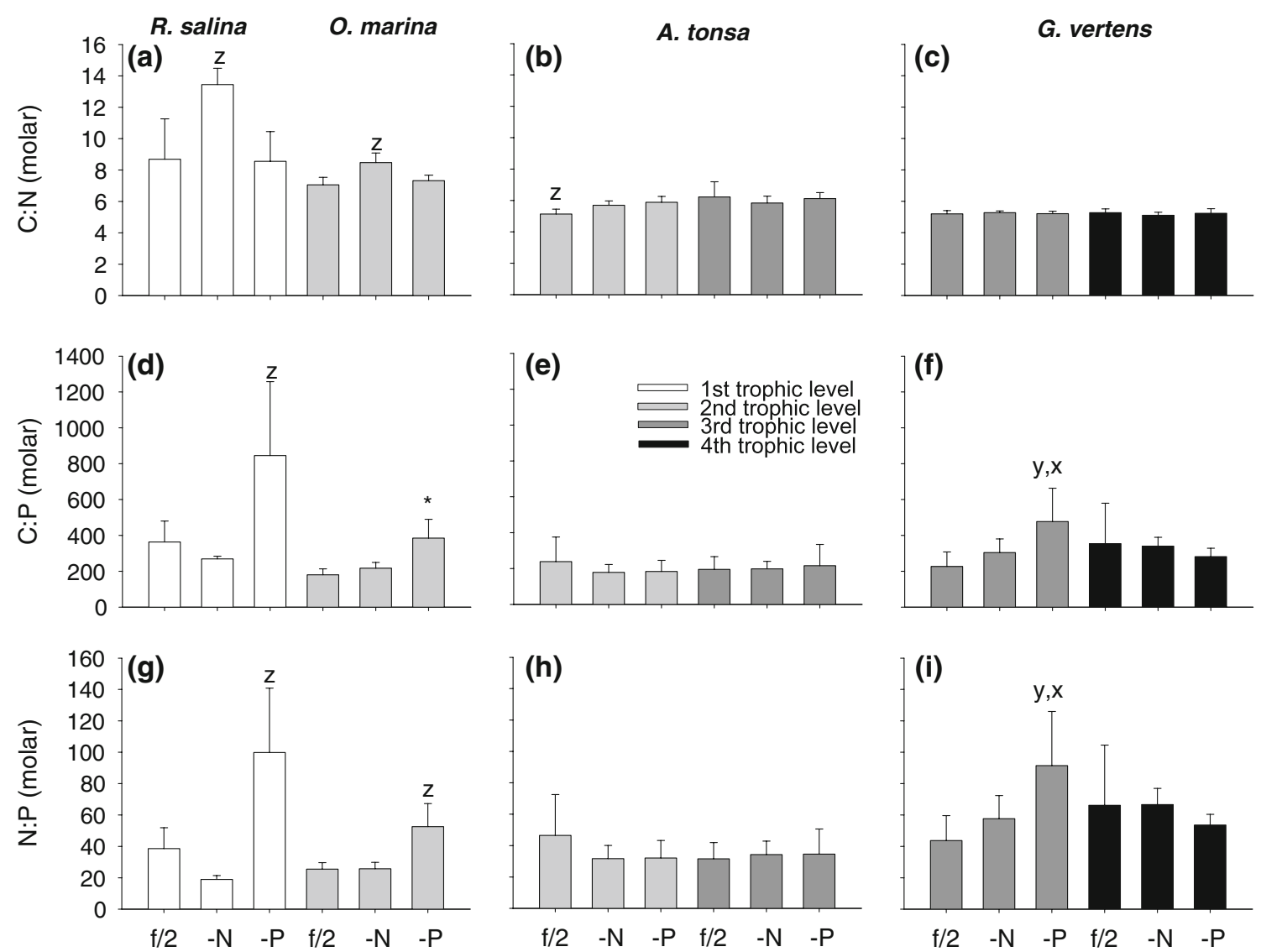

Fig. 1 Stoichiometric measures a-c C:N, $\mathbf{d}-\mathbf{f}$ C:P and $\mathbf{g}-\mathbf{i} \mathrm{N}: \mathrm{P}$ (mean $+1 \mathrm{SD})$ of nutrient-replete $(f / 2)$ and nutrient-depleted [minus $\mathrm{N}(-\mathrm{N}$; black bars) and minus $\mathrm{P}(-\mathrm{P})]$ members of a three- and four-trophiclevel food chain. Rhodomonas salina (open bars), Oxyrrhis marina (light-grey bars), Acartia tonsa in the second trophic level (light-grey bars) and in the third trophic level (dark-grey bars), Gonionemus vertens in the third trophic level (dark-grey bars) and in the fourth trophic level (black bars). $z$ indicates significant differences to the

Table 1), while no differences were found in the $\mathrm{C}: \mathrm{P}$ ratio (Fig. 1e; Table 1) and the N:P ratio (Fig. 1f; Table 1). Unlike the large differences in fatty acids found in the algae the copepods were reared on, consumers showed no differences between the nutrient treatments in their fatty acid measures (Fig. 2c; Table 2; Table 3 online supplement). Copepods reared on P-limited algae had significantly lower developmental rates (Fig. 3a; Table 1) and higher respiration rates (Fig. 3b; Table 1), when compared to those feeding on nutrient-replete algae. The respiration of A. tons $a$ in the $\mathrm{N}$-limited nutrient treatment was in between that of the two other treatments and showed no differences to either. No differences in survival were detected with respect to the nutrient treatment (Fig. 3c; Table 1).

\section{A. tonsa as second consumer}

In contrast to copepods as primary consumers, secondary consumer copepods showed no differences in any of the other two treatments of the respective organism within the trophic level; $y$ indicates significant differences between $\mathrm{f} / 2$ and $-\mathrm{P}$ within the trophic level; $x$ indicates significant differences between $-\mathrm{P}$ from three- and four-trophic-level food chains, according to $P<0.05$, Tukey's honest significant difference (HSD) test. $n=10$ replicates for R. salina, O. marina and G. vertens, $n=8$ replicates for A. tonsa for each treatment

stoichiometric macronutrient measures (Fig. 1d-f; Table 1), and only the n3:n6 ratio was significantly different between the nutrient treatments in the various fatty acid measures (Fig. 2d; Table 2; Table 3 online supplement). Neither developmental rates (Fig. 3a) nor respiration rates (Fig. 3b), were statistically significantly different among the nutrient treatments. Final densities were also not significantly affected by the food quality of the copepods (Fig. 3c).

\section{A. tonsa between-trophic-level effects}

Significant differences between the trophic levels the copepods fed on were detected in the $\mathrm{C}: \mathrm{N}$ ratio of the copepods. The trophic level also resulted in higher survival, higher developmental rates and lower respiration rates when copepods were the secondary consumer (Table 1; Fig. 3). No differences were found in the fatty acid profiles of $A$. tonsa with regard to their trophic level (Table 2). 
Fig. 2 Fatty acid measures (mean +1 SD) of members of three- and four-trophic-level food chain with $\mathrm{f} / 2$ (open bars) or nutrient-depleted $(-\mathrm{N}$; black bars; -P; hatched bars) treatments of a $R$. salina, b $O$. marina, c A. tonsa at the second trophic level, d A. tonsa at the third trophic level, e $G$. vertens at the third trophic level, and $\mathbf{f} G$. vertens at the fourth trophic level. Note the $\log$ scale. $n 3$ and $n 6$ indicate the position of the double bond in the fatty acids, counting from the terminal methyl carbon. $z$ indicates all nutrient treatments are significantly different, $y$ indicates significant differences to the other two nutrient treatments of the respective organism within the trophic level $(P<0.05$,

Tukey's HSD test). $n=10$ replicates for $R$. salina,

$O$. marina and $G$. vertens, $n=8$ replicates for $A$. tonsa for each treatment. For abbreviations, see Fig. 1

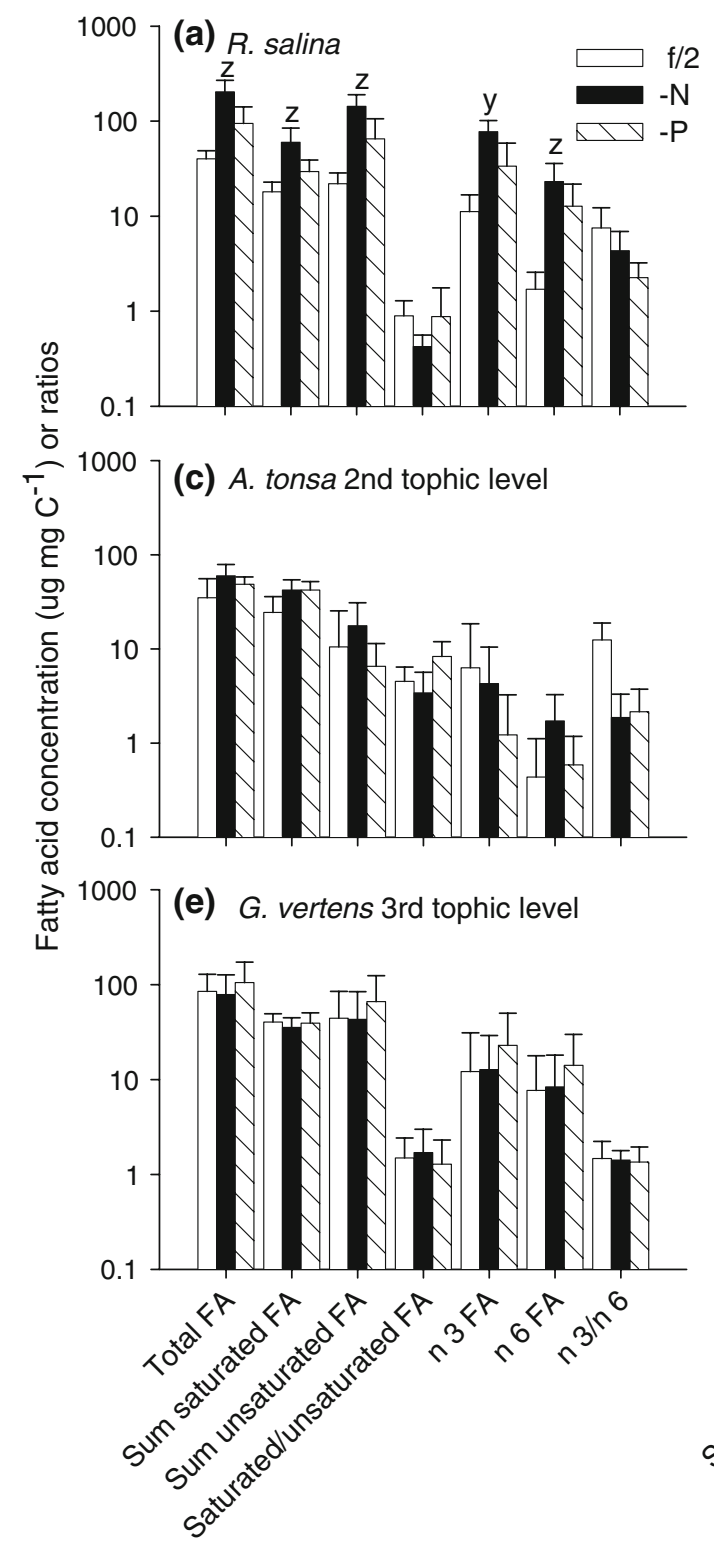

(b) O.marina

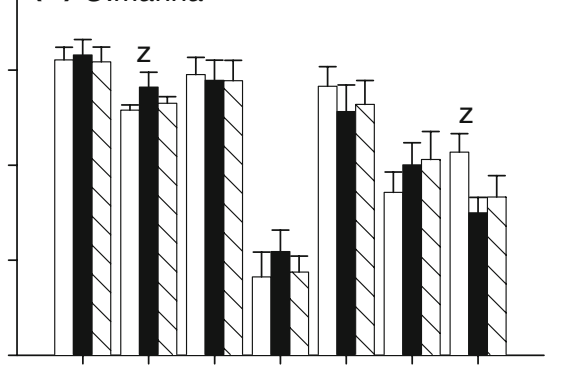

(d) A. tonsa 3rd tophic level

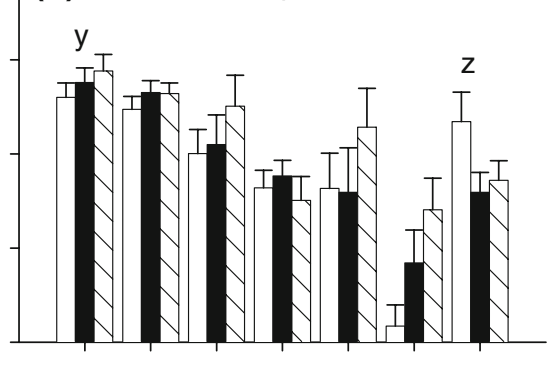

(f) G. vertens 4th trophic level

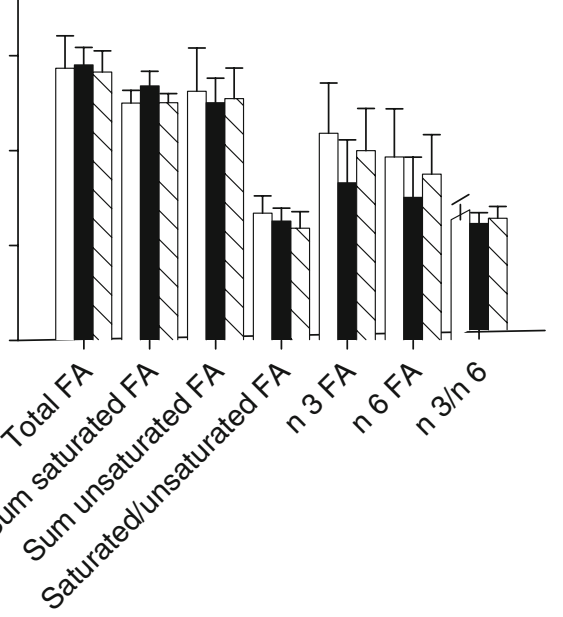

\section{G. vertens}

When the jellyfish were fed on primary consumer copepods, no differences were found in jellyfish $\mathrm{C}: \mathrm{N}$ ratio. However, the C:P and the N:P ratios showed significant differences, with higher ratios in the P-deficient food chain (Fig. 1; Table 1). However, this did not affect the nutritional condition of the jellyfish as expressed by their RNA:DNA ratio. All fed treatments differed significantly from the non-fed control treatment, while no difference occurred within the fed groups of the three-trophic-level food chain (Fig. 4; Table 1), and no differences were detected in the fatty acid measures (Fig. 2e; Table 2; Table 3 online supplement).

The small differences found in the copepods as secondary consumers in the four-trophic-level food chain were not transferred to the top predator of our experimental food chain, the jellyfish. No differences in jellyfish stoichiometry (Fig. 1; Table 1) or the fatty acid profiles were detected (Fig. 2f; Table 2; Table 3 online supplement). Nonetheless, the jellyfish from the two nutrient-stressed treatments did well and did not differ from each other, while, for whatever reason, the $f / 2$ food chain produced jellyfish of significantly poorer condition (Fig. 4). These were, in contrast to the $-\mathrm{N}$ and $-\mathrm{P}$ treatments, statistically not distinguishable from the starvation control (Table 1).

\section{Discussion}

We found large differences in the efficiency of handling excess $\mathrm{C}$ between protozoan and metazoan primary 

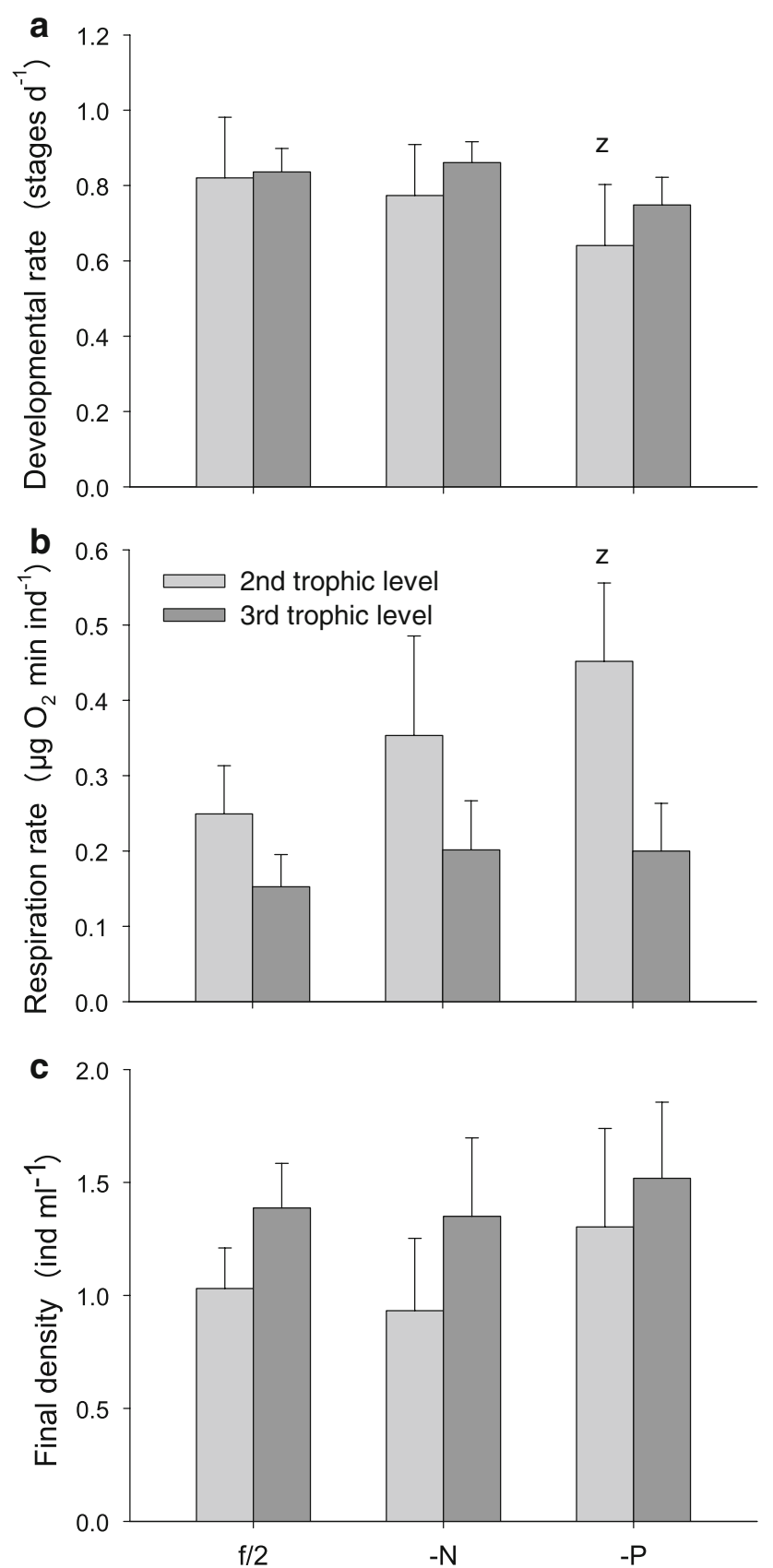

Fig. 3 a Developmental rates, b respiration rates and c final densities (mean $+1 \mathrm{SD}$ ) after 10 days of feeding of A. tonsa on $\mathrm{f} / 2$ and nutrient-depleted $(-\mathrm{N},-\mathrm{P})$ food at the second trophic level (threetrophic-level treatment; light-grey bars) and third trophic level (fourtrophic-level treatment; dark-grey bars). $z$ indicates significant differences between $\mathrm{f} / 2$ and $-\mathrm{P}$ within the given trophic level treatment $(P<0.05$, Tukey's HSD test). $n=8$ replicates for each treatment. For abbreviations, see Fig. 1

consumers. Metazoans showed a higher ability to cope with nutrient-imbalanced food than did protozoan grazers, but even the metazoans showed reduced developmental rates in response to excess C. In contrast, independent from their trophic position, jellyfish are unlikely to suffer from

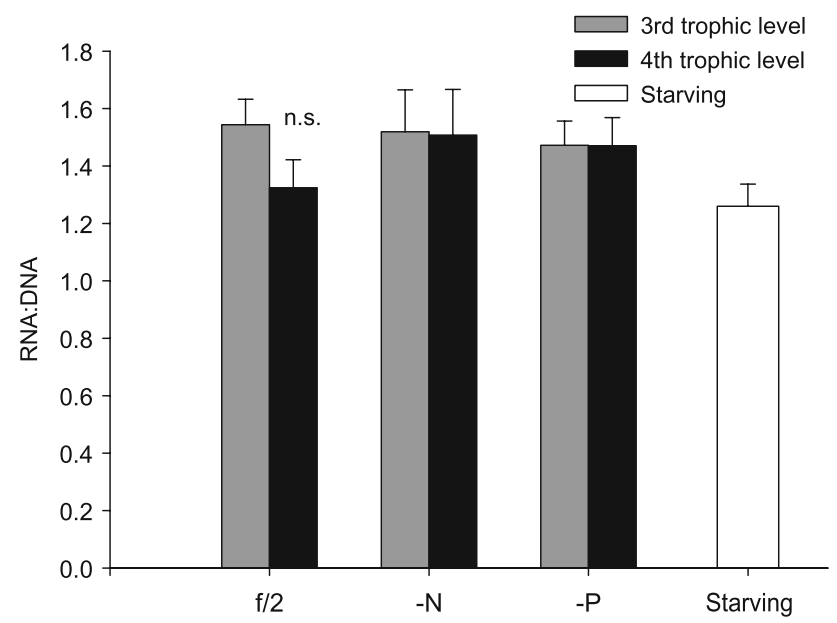

Fig. 4 RNA:DNA ratio (mean $+1 \mathrm{SD}$ ) of $G$. vertens at the third trophic level (dark-grey bars) and the fourth trophic level (black bars) and the starvation control (chequered bar) feeding as the apex predator on the $\mathrm{f} / 2$ or nutrient-depleted $(-\mathrm{N}$, and $-\mathrm{P})$ food chains. No significant differences from the starvation control (n.s.) was determined by $P<0.05$ Tukey's HSD test. For abbreviations, see Fig. 1

P-limited growth, as they show exceptionally high C:N:P ratios.

The primary producers in our study showed significant differences in their biochemical composition depending on the nutrient supply of their culture media. The C:nutrient ratios were increased when specific nutrients were scarce and the stoichiometry of algae varied by a factor of 1.5 for $\mathrm{C}: \mathrm{N}$ and around 5 for $\mathrm{C}: \mathrm{P}$ and $\mathrm{N}: \mathrm{P}$. This is in line with other studies on this subject (Rhee 1978) and homeostasis theory (Sterner and Elser 2002). The fatty acid concentrations of the algae also varied in relation to the nutrient supply, since the nutrient-limited treatments produced higher fatty acid concentrations than the nutrient-replete treatment. Similar effects have been reported by Reitan et al. (1997), Boersma (2000) and Klausmeier et al. (2004). The phenomenon of an enhanced fatty acid production in algae under nutrient limitation has been attributed to the need for C storage under suboptimal growth conditions, such as high light intensities (Urabe and Sterner 1996) or imbalanced nutrient supply (Malzahn et al. 2007; Siron et al. 1989). The fatty acids that were enriched in the nutrient-limited phytoplankton were, among others, eicosapentaenoic acid, docosahexaenoic acid and docosapentaenoic acid, as well as the concentration of unsaturated fatty acids and the ratio of $\mathrm{n} 3: \mathrm{n} 6$. Higher values of these measures are known to reflect higher food quality (MüllerNavarra 2008; Tocher 2003; Watanabe et al. 1983). It is clear that different consumer species (Müller-Navarra 2008) and even different life stages within species differ in their fatty acids demand, and that the demand is also dependent on abiotic parameters like temperature (Farkas et al. 2001; Lee 2001). However, the measures mentioned 
above proved to be robust in their role in determining food quality.

We are aware that our linear food-chain setup is highly artificial, and that both the C:P stoichiometry and the fatty acid concentrations presented in this study are rather high compared to values usually occurring in nature. Although data on marine sestonic C:P ratios are scarce, the majority of the observations are below 300 (Sterner et al. 2008) with just $10 \%$ of the observations being between 300 and 500 . The C:P ratios of our P-stressed algae extended that range, and are more comparable to values frequently found during $P$ depletion in freshwater systems (Elser and Hassett 1994). The fatty acid concentrations presented in this study are also high, but within the range of fatty acid concentrations found in natural seston in the North Sea (recalculated data from Peters et al. 2007). Some individual measures sharply deviated, however, from what can be found in nature. For instance the concentration of n-3 fatty acids in our experimental system was rather high. Clearly, this is because only the generally fatty acid-rich flagellate $R$. salina was used in this study, and it is hard to compare this to bulk seston samples which usually serve as an indication for autotrophic fatty acid supply in field studies. However, assuming a high degree of selective feeding in copepods (Paffenhoefer and Van Sant 1985) bulk seston measurements may also not reflect the diet herbivores actually ingest (Irigoien et al. 2000; Vargas et al. 2006). Thus, the biochemical composition of the autotrophs offered in our experiments might not be irrelevant to natural conditions.

The heterotrophic flagellates in our experiment were not able to completely dampen the stoichiometric imbalances of their prey. The same patterns found in the algae were traceable to the heterotrophic flagellates, even though the ratios were lower. This is in line with studies suggesting that heterotrophic protozoans are rather poor homeostatic regulators (Goldman et al. 1987). An appealing explanation for this is given by Grover and Chrzanowski (2006), who related homeostatic ability to phylogeny. The authors' reasoning was based on heterotrophic metazoans' homeostasis being rather strict, while homeostasis of photoautotrophs is poor in comparison. The close phylogenetic proximity of heterotrophic Protozoa to their photoautotrophic relatives (not to mention mixotrophic protozoans) was used as an argument that these small zooplankters should be rather poor homoeostatic regulators. However, Andersen et al. (1986) reported on a highly efficient $\mathrm{P}$ retention when a phagotrophic microflagellate (Paraphysomonas imperforate) was fed on P-deficient algae, which indicates that the homeostatic flexibility is achieved by the organism being able not only to retain or excrete $\mathrm{P}$ to a larger degree but also by being less constrained than metazoan grazers in their ability to store $\mathrm{C}$, which would also be in line with Grover and Chrzanowskis' (2006) reasoning. Nevertheless, even algae show higher rates of respiration when confronted with high C:nutrient conditions (Hessen and Anderson 2008). One alternative way of handling excess $\mathrm{C}$ in $O$. marina could be the synthesis of fatty acids, as O. marina is known to be able to synthesize especially long-chained highly unsaturated fatty acids de novo (Lund et al. 2008). The flagellates in our experiment obviously took advantage of this option, as they were significantly enriched in fatty acids with respect to their food. Nevertheless, there were no differences in the fatty acid measures between the different nutrient treatments in $O$. marina. Thus they enriched themselves in fatty acids to a certain level independently from the $\mathrm{C}$ supply of the ingested prey.

Interestingly, not only the protozoan grazers, but also the metazoan grazer in our experiment suffered from nutritional imbalances of their prey. We found significantly reduced developmental rates of copepodites reared on P-limited algae. In this context, the most interesting result here is that algae grown under $\mathrm{P}$ limitation produced food of poor quality in terms of their C:P stoichiometry, but superior food with respect to fatty acids. This contrasts with the green algae Scenedesmus obliquus, another model organism commonly used in food-quality experiments (Boersma 2000; Müller-Navarra 1995), in which both C:P stoichiometry and fatty acids were of inferior quality when the organism was grown under P-stress. The opposite response in terms of fatty acids and stoichiometry in $R$. salina makes the algae a perfect prey with which to disentangle the issue of compound-specific growth limitation of grazers and allowed Malzahn et al. (2007) to conclude that, for larval herring, mineral requirements have to be satisfied first, before macromolecules can enhance or limit growth. This reasoning also seems to account for the reduced growth of the copepods in this study when they were fed on algae high in C:P, but rich in fatty acid.

Contrasting with a number of calanoid copepod species, A. tonsa usually does not store large amounts of energy in the form of lipids (Mauchline 1998) and large variations with respect to their fatty acid concentrations are not displayed. Consequently, $A$. tonsa has only a few possibilities to adjust its $\mathrm{C}: \mathrm{N}: \mathrm{P}$ ratio in relation to the food sources used and thus its flexibility is limited. Contrasting to other studies, which reported that the consumer fatty acid profiles mostly reflected the profiles of their prey (Desvilettes et al. 1997), this was not the case for copepods in this study, irrespective of the trophic level they were feeding on. However, when copepods were secondary consumers, they were clearly depleted in fatty acids relative to their fatty acid-rich prey, and significances between nutrient treatments could only be traced from supply to consumers in terms of n3:n6 fatty acid ratios. The strong enrichment in lipids of protozoan grazers in relation to their autotrophic prey has previously been described as the mechanism 
behind trophic upgrading (e.g. Bec et al. 2006; Boechat and Adrian 2005).

In this context another question arises: how do the copepods handle the excess $\mathrm{C}$ ? We observed higher respiration rates when copepods were primary consumers, feeding on high algal $\mathrm{C}$ concentrations in comparison to those feeding on low $\mathrm{C}$ diets. Increased respiration as a mechanism to dispose of excess $\mathrm{C}$ has been suggested by several authors for daphnids (Darchambeau et al. 2003; Jensen and Hessen 2007; Plath and Boersma 2001) and locusts (Zanotto et al. 1997). The responsible mechanism for the enhanced respiration is as yet unknown, but increased muscular activity is discussed in this context (Plath and Boersma 2001). Another potential source of increased respiration rates is feeding-induced thermogenesis (Staples et al. 2004; Zanotto et al. 1997). Heat could be produced by fuelling two opposing enzymatic reactions at the same time, which is costly in terms of energy, but no net changes in either the concentration of substrate or product occurs (Newsholme and Crabtree 1976; Newsholme et al. 1972). Along with slower developmental rates, which are reported for microcrustaceans feeding on highly nutritionally imbalanced algae (Andersen et al. 2004), the higher respiration rates presented here are in line with other studies (Jensen and Hessen 2007) and clearly show that the copepods had difficulties handling excess $\mathrm{C}$ to such an extent that somatic growth was depressed. We did not measure respiration rates of $O$. marina in this study, but soon after this experiment, we performed measurements of growth and respiration rates of $O$. marina under almost identical conditions (Hantzsche and Boersma, in review). We found that protozoan grazers indeed reacted in the same way as our metazoan grazers. Flagellates reared on P-deficient diets had significantly lower growth rates along with significantly higher respiration rates. Respiring excess $\mathrm{C}$ seems therefore also to be realized in protist grazers when faced with unbalanced diets. In contrast to the copepods, the protozoan grazers were not able to completely dampen the nutritional imbalances of their prey.

The lack of bones, scales and similar P-rich structures in jellyfish implies that the demand for $\mathrm{P}$ is low compared to other animals. A large proportion of gelatinous zooplankton, in contrast, consists of mesogloea, which, depending on particular species, is almost cell free. The mesogloea is mainly made of glycoproteins and carbohydrates, and thus, the biomass of a jellyfish consists mainly of ribosome-free C-rich tissue. In the present study this is well reflected by the high $\mathrm{C}: \mathrm{P}$ ratios of jellyfish, which were comparable to those of their prey and in consequence, make them less susceptible to $\mathrm{P}$-poor periods. This places $\mathrm{C}$ in the position of being the potentially limiting element.

In our linear food chains we excluded the possibility of copepods being omnivorous by providing either phytoplankton or microzooplankton as food. Based upon studies on the effect of omnivory on consumer performance in three-level food chains (Diehl and Feißel 2000), it can be speculated that simultaneous supply of both phytoplankton and zooplankton might have resulted in even better copepod performance than when copepods were feeding on microzooplankton alone.

In cases where autotrophic quality was low in the present study, copepods reared as secondary consumers grew faster than those reared as primary consumers, while no differences occurred between copepods as primary or secondary consumer when autotrophic quality was high. In a broader sense this means that when stoichiometric autotrophic quality is beyond the threshold elemental ratio, i.e. the ratio beyond consumer growth is limited by imbalanced nutrient supply (e.g. Frost et al. 2006), an intermediary consumer, in our case $O$. marina, can increase higher order consumer production due to their expenditure of excess C. For the price of lower growth rates and reproduction, these intermediary consumers transform the imbalanced autotrophic elemental supply towards more desired, balanced nutrient ratios for the next consumer level. If these intermediary consumers are abundant enough, the counterintuitive situation may arise that an extra consumer level increases higher trophic level production by expending $\mathrm{C}$. To support this provocative reasoning based on laboratory observations with data from natural aquatic environments would be a great challenge, contributing to further understanding of the loss of overall biomass from one trophic level to the next. To this end there is a need to test this hypothesis intensively and apply such approaches to natural settings in the future.

Acknowledgments We would like to thank an anonymous reviewer and Sebastian Diehl for careful reading of the manuscript and their fruitful thoughts and comments, which improved the quality of the manuscript. K. L. S. is funded by the German Science Foundation (DFG AB 289/2-1) and this study is part of the AWI Food Web project. This study complies with the current German law on animal studies.

\section{References}

Andersen OK, Goldman JC, Caron DA, Dennett MR (1986) Nutrient cycling in a microflagellate food chain. 3. Phosphorus dynamics. Mar Ecol Prog Ser 31:47-55

Andersen T, Elser JJ, Hessen DO (2004) Stoichiometry and population dynamics. Ecol Lett 7:884-900

Anderson TR, Pond DW (2000) Stoichiometric theory extended to micronutrients: comparison of the roles of essential fatty acids, carbon, and nitrogen in the nutrition of marine copepods. Limnol Oceanogr 45:1162-1167

Anderson TR, Boersma M, Raubenheimer D (2004) Stoichiometry: linking elements to biochemicals. Ecology 85:1193-1202

Attrill MJ, Wright J, Edwards M (2007) Climate-related increases in jellyfish frequency suggest a more gelatinous future for the North Sea. Limnol Oceanogr 52:480-485 
Bakker C (1980) On the distribution of Gonionemus vertens A. Agassiz (Hydrozoa, Limnomedusae), a new species in the eelgrass beds of Lake Grevelingen (S.W. Netherlands). Hydrobiol Bull 14:186-195

Bec A, Martin-Creuzburg D, von Elert E (2006) Trophic upgrading of autotrophic picoplankton by the heterotrophic nanoflagellate Paraphysomonas sp. Limnol Oceanogr 51:1699-1707

Bligh EG, Dyer WJ (1959) A rapid method for total lipid extraction and purification. Can J Biochem Physiol 37:911-917

Boechat IG, Adrian R (2005) Biochemical composition of algivorous freshwater ciliates: you are not what you eat. FEMS Microbiol Ecol 53:393

Boersma M (2000) The nutritional quality of P-limited algae for Daphnia. Limnol Oceanogr 45:1157-1161

Boersma M, Becker C, Malzahn AM, Vernooij S (2009) Food chain effects of nutrient limitation in primary producers. Mar Freshwater Res (in press)

Chu FLE, Lund ED, Podbesek JA (2008) Quantitative significance of n-3 essential fatty acid contribution by heterotrophic protists in marine pelagic food webs. Mar Ecol Prog Ser 354:85-95

Clemmesen C (1993) Improvements in the fluorimetric determination of the RNA and DNA content of individual marine fish larvae. Mar Ecol Prog Ser 100:177-183

Darchambeau F, Faerøvig PJ, Hessen DO (2003) How Daphnia copes with excess carbon in its food. Oecologia 136:335-346

Denno RF, Fagan WF (2003) Might nitrogen limitation promote omnivory among carnivorous arthropods? Ecology 84:25222531

Desvilettes C, Bourdier G, Amblard C, Barth B (1997) Use of fatty acids for the assessment of zooplankton grazing on bacteria, protozoans and microalgae. Freshwater Biol 38:629-637

Dickman EM, Newell JM, Gonzalez MJ, Vanni MJ (2008) Light, nutrients, and food-chain length constrain planktonic energy transfer efficiency across multiple trophic levels. Proc Natl Acad Sci USA 105:18408-18412

Diehl S, Feißel M (2000) Effects of enrichment on three-level food chains with omnivory. Am Nat 155:200-218

Elser JJ, Hassett RP (1994) A stoichiometric analysis of the zooplankton-phytoplankton interaction in marine and freshwater ecosystems. Nature 370:211-213

Elser JJ et al (2000) Nutritional constraints in terrestrial and freshwater food webs. Nature 408:578-580

Farkas T, Fodor E, Kitajka K, Halver JE (2001) Response of fish membranes to environmental temperature. Aquat Res 32: 645-655

Folch J, Lees M, Stanley GHS (1957) A simple method for the isolation and purification of total lipids from animal tissues. J Biol Chem 226:497-509

Frost PC et al (2006) Threshold elemental ratios of carbon and phosphorus in aquatic consumers. Ecol Lett 9:774-779

Goldman JG, Caron DA, Dennett MR (1987) Nutrient cycling in a microflagellate food chain. 4. Phytoplankton-microflagellate interactions. Mar Ecol Prog Ser 38:75-87

Grasshoff K, Kremling K, Erhardt M (1999) Methods of seawater analysis, 3rd edn. Wiley-VCH, Weinheim

Grover JP, Chrzanowski TH (2006) Stoichiometry and growth kinetics in the "smallest zooplankton" phagotrophic flagellates. Arch Hydrobiol 167:467

Guillard R, Ryther J (1962) Studies of marine planktonic diatoms. Can J Microbiol 8:229-239

Gulati RD, DeMott WR (1997) The role of food quality for zooplankton: remarks on the state-of-the-art, perspectives and priorities. Freshwater Biol 38:753-768

Hessen DO, Anderson TR (2008) Excess carbon in aquatic organisms and ecosystems: physiological, ecological, and evolutionary implications. Limnol Oceanogr 53:1685-1696
Irigoien X, Head RN, Harris RP, Cummings D, Harbour D, MeyerHarms B (2000) Feeding selectivity and egg production of Calanus helgolandicus in the English Channel. Limnol Oceanogr 45:44-54

Jensen T, Hessen D (2007) Does excess dietary carbon affect respiration of Daphnia? Oecologia 152:191

Jindra M, Sehnal F (1990) Linkage between diet humidity, metabolic water production and heat dissipation in the larvae of Galleria mellonella. Insect Biochem 20:389-395

Kagata H, Ohgushi T (2007) Carbon-nitrogen stoichiometry in the tritrophic food chain willow, leaf beetle, and predatory ladybird beetle. Ecol Res 22:671

Klausmeier CA, Litchman E, Daufresne T, Levin SA (2004) Optimal nitrogen-to-phosphorus stoichiometry of phytoplankton. Nature 429:171-174

Le Pecq JB, Paoletti C (1966) A new fluorometric method for RNA and DNA determination. Anal Biochem 17:100-107

Lee S-M (2001) Review of the lipid and essential fatty acid requirement of rockfish (Sebastes schlegeli). Aquat Res 32:8-17

Lund ED, Chu FE, Harvey E, Adlof R (2008) Mechanism(s) of long chain n-3 essential fatty acid production in two species of heterotrophic protists: Oxyrrhis marina and Gyrodinium dominans. Mar Biol 155:23

Lynam CP, Heath MR, Hay SJ, Brierley AS (2005) Evidence for impacts by jellyfish on North Sea herring recruitment. Mar Ecol Prog Ser 298:157-167

Malzahn AM, Aberle N, Clemmesen C, Boersma M (2007) Primary production under nutrient limitation indirectly affects larval fish condition. Limnol Oceanogr 52:2062-2071

Mauchline J (1998) The biology of calanoid copepods. Academic Press, San Diego

Mills CE (2001) Jellyfish blooms: are populations increasing globally in response to changing ocean conditions? Hydrobiologia 451:55

Müller-Navarra DC (1995) Biochemical versus mineral limitation in Daphnia. Limnol Oceanogr 40:1209-1214

Müller-Navarra DC (2008) Food web paradigms: the biochemical view on trophic interactions. Int Rev Hydrobiol 93:489-505

Newsholme EA, Crabtree B (1976) Substrate cycles in metabolic regulation and in heat generation. Biochem Soc Symp 41:61-109

Newsholme EA, Crabtree B, Higgins SJ, Thornton SD, Start C (1972) The activities of fructose diphosphatase in flight muscles from bumble-bee and the role of this enzyme in heat generation. Biochem J 128:89-97

Paffenhoefer GA, Van Sant KB (1985) The feeding response of a marine planktonic copepod to quantity and quality of particles. Mar Ecol Prog Ser 27:55-65

Peters J, Dutz J, Hagen W (2007) Role of essential fatty acids on the reproductive success of the copepod Temora longicornis in the North Sea. Mar Ecol Prog Ser 341:153-163

Plath K, Boersma M (2001) Mineral limitation of zooplankton: stoichiometric constraints and optimal foraging. Ecology 82: 1260-1269

Purcell JE, Arai MN (2001) Interactions of pelagic cnidarians and ctenophores with fish: a review. Hydrobiologia 451:27-44

Reitan KI, Rainuzzo JR, Oie G, Olsen Y (1997) A review of the nutritional effects of algae in marine fish larvae. Aquaculture 155:207-221

Rhee GY (1978) Effects of N:P atomic ratios and nitrate limitation on algal growth, cell composition, and nitrate uptake. Limnol Oceanogr 23:10-25

Schoo KL, Aberle N, Malzahn AM, Boersma M (2009) Does the nutrient stoichiometry of primary producers affect the secondary consumer Pleurobrachia pileus? Aquat Ecol (in press)

Siron R, Giusti G, Berland B (1989) Changes in the fatty-acid composition of Phaeodactylum tricornutum and Dunaliella 
tertiolecta during growth and under phosphorus deficiency. Mar Ecol Prog Ser 55:95-100

Staples JF, Koen EL, Laverty TM (2004) 'Futile cycle' enzymes in the flight muscles of North American bumblebees. J Exp Biol 207:749-754

Sterner RW, Elser JJ (2002) Ecological stoichiometry: the biology of elements from molecules to the biosphere. University Press, Princeton

Sterner RW et al (2008) Scale-dependent carbon:nitrogen:phosphorus seston stoichiometry in marine and freshwaters. Limnol Oceanogr 53:1169-1180

Tocher DR (2003) Metabolism and functions of lipids and fatty acids in teleost fish. Rev Fish Sci 11:107-184
Urabe J, Sterner RW (1996) Regulation of herbivore growth by the balance of light and nutrients. Proc Natl Acad Sci 93:8465-8469

Vargas CA, Escribano R, Poulet S (2006) Phytoplankton food quality determines time windows for successful zooplankton reproductive pulses. Ecology 87:2992-2999

Watanabe T, Kitajima C, Fujita S (1983) Nutritional values of live organisms used in Japan for mass propagation of fish: a review. Aquaculture 34:115-143

Zanotto FP, Gouveia SM, Simpson SJ, Raubenheimer D, Calder PC (1997) Nutritional homeostasis in locusts: is there a mechanism for increased energy expenditure during carbohydrate overfeeding? J Exp Biol 200:2437-2448 